This item was submitted to Loughborough's Research Repository by the author.

Items in Figshare are protected by copyright, with all rights reserved, unless otherwise indicated.

\title{
The impact of intensified training with a high or moderate carbohydrate feeding strategy on resting and exercise-induced oxidative stress
}

PLEASE CITE THE PUBLISHED VERSION

http://dx.doi.org/10.1007/s00421-015-3162-4

\section{PUBLISHER}

(c) Springer Verlag

\section{VERSION}

AM (Accepted Manuscript)

\section{PUBLISHER STATEMENT}

This work is made available according to the conditions of the Creative Commons Attribution-NonCommercialNoDerivatives 4.0 International (CC BY-NC-ND 4.0) licence. Full details of this licence are available at: https://creativecommons.org/licenses/by-nc-nd/4.0/

\section{LICENCE}

CC BY-NC-ND 4.0

\section{REPOSITORY RECORD}

Wadley, Alexander J., Sophie C. Killer, Ida S. Svendsen, and Michael Gleeson. 2019. "The Impact of Intensified Training with a High or Moderate Carbohydrate Feeding Strategy on Resting and Exercise-induced Oxidative Stress". figshare. https://hdl.handle.net/2134/17105. 


\section{The impact of intensified training with a high or moderate carbohydrate feeding strategy on resting and exercise-induced oxidative stress}

Alex, J. Wadley ${ }_{1,2 * *}$ Sophie, C. Killer ${ }_{1}$ Ida, S. Svendsen ${ }_{1} \&$ Michael Gleeson ${ }_{1}$

4

5 i School of Sport, Exercise \& Health Sciences, Loughborough University, Leicestershire, LE11 3TU*

$6{ }_{2}$ Institute of Science and the Environment, University of Worcester, Worcester, WR2 AJ

$7 \quad * \quad$ all work was undertaken at Loughborough University, UK

$8 * * \quad$ present address

9

10 Running Title: Intensified training and oxidative stress

11 Word Count: 4501

13 Address for correspondence:

14 Dr Alex Wadley

15 Institute of Science and the Environment

16 University of Worcester

17 Henwick Grove, WR2 6AJ

18 United Kingdom

19 Email: a.wadley@worc.ac.uk

20 Phone: 01905542720

21 
Purpose: This study investigated the impact of intensified training (IT) and carbohydrate (CHO) supplementation on resting and exercise-induced oxidative stress.

Methods: Male cyclists $\left(\mathrm{n}=13\right.$, mean $\pm \mathrm{SD}$ : age $25 \pm 6$ years; $\left.\dot{v} \mathrm{O}_{2 \max } 72 \pm 5 \mathrm{ml} / \mathrm{kg} / \mathrm{min}\right)$ undertook two 9-day periods of endurance-based IT. In a counterbalanced, crossover and double-blinded study design, participants completed IT whilst ingesting high ( $\mathrm{H}-\mathrm{CHO})$ or moderate (M-CHO) $\mathrm{CHO}$ beverages before (HCHO: 24g vs. MCHO: 2g), during (HCHO: 60g/hour vs. M-CHO: 20g/hour) and after training sessions (HCHO: 44g vs. M-CHO: 10g). Participants completed fasted performance trials without $\mathrm{CHO}$ on days 2, 6 and 10. Blood samples were taken before and immediately after exercise to assess plasma oxidative stress.

Results: Resting thiol (-SH) and catalase (CAT) activities decreased following 6 days of IT, independent of CHO condition (-SH $(\mu \mathrm{M}$ oxidised NADPH): $\mathrm{H}-\mathrm{CHO}-14.0 \pm 18.8, \mathrm{M}-\mathrm{CHO}-20.4 \pm 20.3$ and CAT $(\mathrm{nmol} / \mathrm{min} / \mathrm{ml}): \mathrm{H}-\mathrm{CHO}-12.5 \pm 12.5, \mathrm{M}-\mathrm{CHO}-6.0 \pm 4.5 ;$ all $\mathrm{p}<.05)$. Resting total antioxidant capacity $(\mathrm{TAC})$ was reduced after IT in M-CHO. All exercise bouts elicited significant increases in CAT, TAC, protein carbonylation (PC) and lipid hydroperoxides $(\mathrm{LOOH})$, independent of $\mathrm{CHO}$ condition $(\mathrm{p}<.05)$. The magnitude of increase in PC and LOOH was greater on days 6 and 10 compared to day 2 in both conditions. Conclusions: Short-term IT caused reductions in resting antioxidant capacity in trained cyclists. Exerciseinduced increases in $\mathrm{PC}$ and $\mathrm{LOOH}$ were exaggerated as a result of IT; however, these responses were independent of carbohydrate intake before, during and after the preceding IT sessions.

\section{Introduction}

Periods of intensified training (IT) are commonly utilised by athletes throughout a season; however, excessive physical overload and or inadequate recovery can induce a state of overtraining (OT). Exercise of sufficient intensity (21) and duration (3) is accompanied by a transient increase in oxidative stress, whereby the production of reactive oxygen species (ROS) overwhelms their clearance by antioxidants $(3,41)$. ROS are known to have various roles in regulating tissue function $(20,32)$ and cellular signalling pathways in response to exercise that are involved in training adaptations $(11,17)$. Despite this, exercise-induced changes in ROS are thought to parallel the model of hormesis (33), whereby an optimal threshold between subtle control of cellular 
OT athletes, where resting and acute exercise-induced oxidative stress are modulated following periods of aerobic (39) and resistance-based IT (22).

Previous studies have reported that resting markers of oxidative stress, such as plasma protein carbonylation (PC) $(22,39,46)$ and lipid peroxidation $(10,22,46)$ are elevated to a greater extent following IT periods of between 4-12 weeks, when compared with habitual training regimens. The effects of IT on antioxidant defences are more complex, with antioxidant enzyme activities increasing $(22,31)$ and total plasma antioxidant capacity (TAC) decreasing during these periods of IT $(22,31)$. Phagocytic cells (e.g. neutrophils, monocytes and macrophages) that infiltrate damaged muscle fibres and other active tissues during exercise may generate large quantities of ROS that deplete extracellular antioxidants, promoting the activity and release of endogenous antioxidants into the circulation. The resulting changes in resting oxidative stress may also modulate the acute oxidative stress response to exercise, with reports of exaggerated $(31,40)$ and suppressed $(39)$ oxidative stress observed following acute exercise challenges in athletes undergoing IT. These inconsistencies can be attributed to the range of study designs utilised, with respect to the duration and intensity of the IT period, and also the timing of blood measures following the change in overload stimulus. To our knowledge, resting and exercise-induced oxidative stress has not been assessed in the immediate days following a period of training overload.

Nutritional strategies to modulate resting and acute changes in oxidative stress following exercise are common. Carbohydrate $(\mathrm{CHO})$ ingestion is routinely used by athletes before, during and after exercise to improve physical performance, maintain a high average training workload and optimise recovery (15). In addition, $\mathrm{CHO}$ ingestion maintains intracellular reduced nicotinamide adenine dinucleotide phosphate (NADPH) concentrations, a coenzyme essential in buffering ROS production and potentially delaying muscle fatigue (9), via the conversion of six to five carbon sugars in the pentose phosphate pathway. Previous studies have reported both no differences $(27,42)$ and marked attenuations in oxidative stress following single bouts of sub-maximal exercise, whilst ingesting a high versus placebo (non-CHO) beverage $(24,25)$. These mixed findings may be attributed to the varying doses of $\mathrm{CHO}$ administered, along with other aspects of study design. To our knowledge, no studies have assessed the influence of $\mathrm{CHO}$ supplementation on markers of resting and exerciseinduced oxidative stress during or following a period of IT. Using the recommended guidelines for the upper limit of $\mathrm{CHO}$ intake with exercise, Halson et al, 2004 reported that a high $\mathrm{CHO}$ intake before $(6.4 \% \mathrm{CHO}$, providing $32 \mathrm{~g} \mathrm{CHO}$ ), during (6.4\% $\mathrm{CHO}$, providing $32 \mathrm{~g} \mathrm{CHO}$ per hour) and after (20\% $\mathrm{CHO}$, providing $200 \mathrm{~g}$ $\mathrm{CHO}$ ) the training sessions of short term IT (i.e. 11 days), attenuated decrements in both physical and 
psychological performance compared to a moderate carbohydrate beverage ( $2 \% \mathrm{CHO}$, providing $10 \mathrm{~g}$ before, $10 \mathrm{~g}$ per hour during and $20 \mathrm{~g} \mathrm{CHO}$ after exercise, respectively) (1, 13). This study demonstrates the significant physiological and psychological effects that the composition of pre-exercise CHO beverages can confer, beyond comparisons of $\mathrm{CHO}$ versus non-CHO placebo. Indeed, athletes now utilise highly specific guidelines (ACSM) on the required macronutrient intake before, during and after highly demanding exercise, to maintain physical workload and optimise performance (35). Accordingly, the aims of the present study were to investigate the impact of a short-term period of IT on resting and exercise-induced oxidative stress, and to assess these responses under conditions of high and moderate $\mathrm{CHO}$ intake during the IT period. We tested the hypothesis that IT would increase resting and exercise-induced changes in oxidative stress, with high carbohydrate consumption during the preceding training sessions dampening this response.

Keywords: Overtraining, antioxidant, reactive oxygen species, glucose, performance

\section{Abbreviations:}

ANOVA: Analysis of Variance, CAT: Catalase activity, M-CHO: Moderate carbohydrate group, CV: Coefficient of variance, DNA: deoxyribonucleic acid, DNPH: Dinitrophenylhydrazine, ELISA: Enzyme Linked Immunosorbent Assay, FRAP: Ferric Reducing Ability of Plasma, H-CHO: High carbohydrate group, $\mathrm{HCl}$ : Hydrochloric acid, HR $\mathrm{MAX}_{\mathrm{X}}$ : Maximum heart rate, HRP: Horseradish Peroxidase, IT: Intensified training, LOOH: Lipid Hydroperoxides, $\mathrm{NaCl}$ : Sodium Chloride, NADH: reduced nicotinamide adenine dinucleotide, OT: Overtraining, PC: Protein Carbonyl, ROS: Reactive oxygen species, SD: Standard deviation, TAC: Total antioxidant capacity, TBS: Tris-Buffered Saline, $-\mathrm{SH}$ : Total thiol activity, $\mathrm{VCO}_{2}$ : Carbon dioxide production, $\mathrm{VO}_{2}$ : Oxygen consumption, $\mathrm{VO}_{2 \mathrm{MAX}}$ : Maximum oxygen consumption.

\section{Methods}

This investigation formed part of a larger investigation assessing parameters of sleep quality, hormonal balance and immune function $(18,19,38)$.

\section{Participants}



percentage $13.4 \pm 4.1 \%$; maximal oxygen consumption $\left(\dot{V} O_{2}{ }_{\mathrm{MAX}}\right) 72.2 \pm 4.9 \mathrm{ml} / \mathrm{kg} / \mathrm{min}$ ) were recruited for this double-blind, placebo-controlled crossover design study. All participants gave their written informed consent and the investigation was approved by the Loughborough University ethical review committee. Inclusion criteria were based on participants being highly trained ( $\dot{V} O_{2} \mathrm{MAx}>64 \mathrm{ml} / \mathrm{kg} / \mathrm{min}$ ) experienced cyclists, engaging in at least 6 hours of cycling training per week. Participants were excluded if they were smokers or had a current illness or infection.

Study design

Each participant completed two 9-day periods of intensified training (IT), separated by a 15-day washout period (Figure 1). During one period of IT, participants were provided with high CHO beverage before, during and after every training session $(\mathrm{H}-\mathrm{CHO})$ with additional protein during recovery (Table 1). Participants also undertook an identical period of IT with a taste-matched moderate $\mathrm{CHO}$ beverage (M-CHO) with no protein during the recovery period. The two IT periods were completed in a randomised, counter-balanced order. During and after both periods of IT, each participant undertook a standardised 1 hour performance trial (PT) in an overnight-fasted state on days 2, 6 and 10 (i.e. the morning after the final IT session), with resting and acute changes in markers of oxidative stress assessed on those days. Participants were instructed to not take any supplements or anti-inflammatory drugs during the study. During the 15-day washout period, participants were encouraged to recover fully before returning to normal training.

Pre-trial assessments

All participants visited Loughborough University for determination of baseline demographics and $\dot{V} \mathrm{O}_{2}$ max. Height and weight were recorded (Seca Alpha, Hamburg, Germany) and body composition determined by DEXA at the Gatorade Sports Science Institute. An incremental cycle test to exhaustion on an electronically braked ergometer (Lode Excalibur Sport, Groningen, Netherlands) was used for determination of $\dot{V} \mathrm{O}_{2}$ MAX. Expired gas composition was monitored continually throughout the test and breath-by-breath analysis was performed automatically with a Moxus metabolic systems analyser (AEI Technologies Inc., Naperville, IL, USA). Heart rate (HR) was recorded continually using short range telemetry (Polar RS800CX, Polar, Kempele, Finland) and ratings of perceived exertion were recorded from participants during the final minute of each stage. 
143 A respiratory exchange ratio $>1.10$ and a plateau in $\mathrm{VO}_{2}$ despite increasing workload were used to confirm that

$144 \dot{V} O_{2}$ MAX had been reached (14).

145 Participants fulfilling the inclusion criteria were provided with HR monitors (Suunto, Vantaa, Finland)

146 and SRM power meters (SRM Shimano DA7900 PowerMeter). All participants were then requested to train for

147 two weeks according to their normal programmes and to record this information in the training diaries provided

148 (baseline training load). This information was used to generate the IT protocols. Baseline assessments of 149 psychological well-being were also determined, using Daily Analysis of Life Demands of Athletes (DALDA B)

150 (36) and Profile of Mood States (POMS-65) (12) questionnaires. These standardised questionnaires measured the manifestation of stress symptoms and mood state, respectively. No participants exhibited symptoms of overreaching during their pre-trial phase according to the guidelines set by Meeusen and colleagues (4).

\section{Intensified training programme}

Participants were prescribed an individualised training plan based on their baseline training load and the results obtained from their $\dot{V} O_{2}$ MAX test. During each period of IT, total training volume was doubled compared to baseline. Further, time spent training at high-intensity $\left(>82 \% \mathrm{HR}_{\mathrm{MAX}}\right)$ was more than trebled. Participants were prescribed two training sessions per day, with every session including a component of high intensity exercise (82-95\% $\left.\mathrm{HR}_{\mathrm{MAX}}\right)$. On days 1, 2, 5, 6 and 8 of both IT periods, participants attended supervised training sessions at Loughborough University. All other training was performed in their own time on a bicycle equipped with a power meter (SRM PowerMeter Shimano DA7950 compact, SRM International, Jülich, Germany) and HR continuously measured (Suunto, Valaa, Finland). Standardised training sessions were administered the day before each performance test. Mood-state profiles were re-assessed on days 6 and 10 .

Nutritional Intervention

During both periods of IT, participants were provided with a specific volume and composition of CHO beverage before ( $<15$ minutes before exercise), during and after ( $<10$ minutes after exercise) every training session (Table 1). The participants were instructed not to consume other sports nutrition supplements during the study period. The prescribed carbohydrate intake for the $\mathrm{H}-\mathrm{CHO}$ condition reflected current ACSM guidelines on the upper range of recommended intakes for endurance exercise training sessions $(60 \mathrm{~g} / \mathrm{h})$, including a high

$171 \mathrm{CHO}$ and protein recovery beverage after training (35). In the M-CHO condition, participants were provided 

informed that the purpose of the study was to monitor the impact of an amino acid recovery pill versus a beverage following exercise only. In non-training periods, participants completed weighed diet diaries for three days prior to (pre-trial and washout) and every day during each experimental period ( $\mathrm{H}-\mathrm{CHO}$ and $\mathrm{M}-\mathrm{CHO})$ in order to monitor daily energy and macronutrient intake. Participants were instructed to consume their normal diet throughout each training period and keep their diets as similar as possible between the two conditions.

\section{Performance testing and blood sampling}

Participants arrived at the laboratory at a standardised time between 06:30-08:30, following an overnight fast for the PT on days 2, 6, and 10. A rested venous blood sample (pre-exercise) was obtained by venepuncture from the antecubital vein of the arm and blood collected into vacutainers containing $\mathrm{K}_{3}$ EDTA anticoagulant (Becton, Dickson \& Company, Oxford, UK). Following a 10-minute warm-up at a self-selected intensity, participants performed an all-out one hour PT on their own bicycles on a turbo trainer (CycleOps Flow). Heart rate was recorded continually during each PT using short range telemetry (Suunto, Valaa, Finland) and power was recorded with SRM power meters (SRM Shimano DA7900 PowerMeter). Participants were provided with a clock during the PT, but blinded their power output, cadence and heart rate data. A second blood sample was taken immediately following cessation of the PT (post-exercise). Blood was centrifuged at $15,600 \mathrm{rpm}(400 \mathrm{~g})$ for 10 minutes at $4^{\circ} \mathrm{C}$. Plasma was then extracted and stored at $-80{ }^{\circ} \mathrm{C}$ until further analysis.

\section{Analytical Measures}

Protein Carbonylation

PC was assessed by ELISA $(4,6)$. Samples were diluted in sodium carbonate buffer $(50 \mathrm{mM}, \mathrm{pH}=9.2)$ to a concentration of $0.05 \mathrm{mg} / \mathrm{ml}$. Samples and standards $(50 \mu \mathrm{L})$ were added in triplicate to a 96 well NUNC maxisorb microtitre plate for 1 hour at room temperature. Bound protein was incubated in the dark for 1 hour at room temperature with 2, 4-dinitrophenylhydrazine (DNPH) $(1 \mathrm{mM}$, in $2 \mathrm{M} \mathrm{HCl})$. All wells were then blocked with TBS Tween $(200 \mu \mathrm{L}, 0.1 \%)$ overnight at $4^{\circ} \mathrm{C}$. Wells were incubated with monoclonal mouse anti-DNP antibody $(50 \mu \mathrm{L}, 1: 1000)$ for 2 hours at $37^{\circ} \mathrm{C}$, followed by peroxidase conjugated rat anti-mouse IgE conjugated HRP $(50 \mu \mathrm{L}, 1: 5000)$ for 1 hour at room temperature. Substrate (0.5 M Citrate phosphate buffer (10 ml, $\mathrm{pH}=5)$, hydrogen peroxide $(8 \mu \mathrm{l})$ and Ortho-Phenylenediamine tablet $(2 \mathrm{mg}) ; 50 \mu \mathrm{L})$ was added to each well and the reaction stopped using sulphuric acid $(50 \mu \mathrm{L}, 2 \mathrm{M})$. The absorbance of each sample was measured at $490 \mathrm{~nm}$ 

standards made in our lab (1.94-4.91 nmol/mg of protein). Protein concentration was determined using the bicinchoninic assay method (37).

\section{Lipid Hydroperoxides}

Lipid hydroperoxide (LOOH) concentrations were assessed using a method originally developed by ElSaadini et al., 1989 (7). Briefly, plasma samples (10 $\mu \mathrm{l})$ were incubated with a reagent mix (100 $\mu \mathrm{L}: 0.2 \mathrm{M}$ Potassium phosphate $(\mathrm{pH}=6.2), 0.12 \mathrm{M}$ potassium iodide, $0.15 \mathrm{mM}$ sodium azide, Triton $\mathrm{X}(2 \mathrm{~g} / \mathrm{l})$, alkylbenzyldimethylammonium $(0.1 \mathrm{~g} / \mathrm{l}), 10 \mu \mathrm{M}$ ammonium molybdate and HPLC grade water) for 30 minutes at room temperature, in the dark. The assay measures the oxidative capacity of LOOH to convert iodide to iodine. Wells were read at $340 \mathrm{~nm}$ (Varioskan Flash, Thermo Fisher Scientific, Leicestershire, UK) and the $/ \mathrm{M} / \mathrm{cm})(7)$.

\section{Total Antioxidant Capacity}

TAC was assessed using the Ferric Reducing Ability of Plasma (FRAP) assay, developed by Benzie et al., 1996 (2). Plasma samples $(10 \mu \mathrm{L})$ and standards $(10 \mu \mathrm{L})$ were incubated with FRAP reagent mix $(300 \mathrm{mM}$

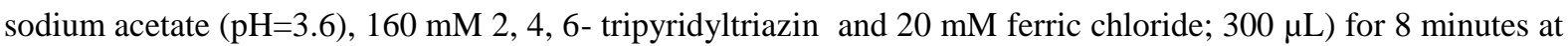
room temperature, and then absorbance was measured at $650 \mathrm{~nm}$ (Varioskan Flash, Thermo Fisher Scientific, Leicestershire, UK). TAC values were obtained using absorbance values of known ascorbic acid concentrations (ascorbic acid, 0-1000 $\mu \mathrm{M}$ ) and expressed as $\mu \mathrm{M}$ of antioxidant power relative to ascorbic acid (26).

\section{Catalase Activity}

The peroxidatic activity of Catalase was measured in plasma (diluted 1:1 with sample buffer [25 mM potassium phosphate, $\mathrm{pH}=7.5,1 \mathrm{mM}$ EDTA and 0.1\% Bovine Serum Albumin]), using a commercially available assay kit, according to the manufacturer's instructions (Cayman Chemical). Enzyme activity was assessed by incubating samples with methanol (100\%), in presence of hydrogen peroxide (0.04 M) and formaldehyde formation measured. Absorbance values were measured at $540 \mathrm{~nm}$ (Varioskan Flash, Thermo $\mu \mathrm{M})$. 
Total thiol (-SH) activity was measured using a commercially available kit according to manufacturer instructions (ab83463, Abcam, Cambridge, UK). Briefly, plasma samples were adjusted to the lowest sample protein concentration $(0.55 \mathrm{mg} / \mathrm{ml}$ protein in assay buffer) and added $(50 \mu \mathrm{L})$ with a reaction mix $(30 \mu \mathrm{L}$ assay buffer $+8 \mu \mathrm{L}$ 5,5'-dithiobis (2-nitrobenzoic) acid (DNTB) $+2 \mu 1$ nicotinamide adenine dinucleotide phosphate (NADPH) per well) to a 96-well microtitre assay plate. Absorbance values were measured at $412 \mathrm{~nm}$ every 5 minutes for 25 minutes to determine the kinetics of the enzymatic reaction (Varioskan Flash, Thermo Fisher Scientific, Leicestershire, $U K$ ). -SH activity was obtained from a standard curve of known 5-thio-2-nitrobenzoic acid (TNB) concentrations (0-50 nmol/well).

Sample size calculation and Statistical Analysis

Power analyses using Gpower3 (8), with significance at .05 and power at .90 , were conducted based upon results from previous studies (43-45) and preliminary pilot work assessing markers of oxidative stress following steady state exercise in young adults. Primary outcome measures of protein carbonylation, lipid peroxidation and total antioxidant capacity were used. A sample size of 13 participants was required to detect differences with an effect size of .24 (medium effect size).

\section{Data Reduction and Statistical Analysis}

Statistical analyses were performed using SPSS (PASW Statistics, 22.0). Shapiro-Wilk tests were used to investigate normal distribution and differences between variables at baseline were assessed using one-way analyses of variance (ANOVA). Total training volume and time spent exercising at high-intensity were assessed by paired sample t-tests. The influence of $\mathrm{CHO}$ ingestion (carbohydrate) on changes in acute (exercise) and resting (day) oxidative stress were assessed by $2 * 2 * 3$ repeated-measures ANOVA (carbohydrate, exercise, day).

257 Changes in performance (mean power (watts) and maximum heart rate (bpm)) and mood-state profiles (DALDA B and POMS-65 TMD) were assessed by $3 * 2$ repeated-measures ANOVA (day, carbohydrate). Changes in macronutrient consumption (total energy intake (kcal), carbohydrate (grams/day $(\mathrm{g} / \mathrm{d}))$, fat (g/d), protein (g/d)) were assessed by $2 * 2$ repeated-measures ANOVA (period (i.e. days 1-6 and days 7-9), carbohydrate). All post hoc analysis of the interaction effects was performed by a test of simple effects by pairwise comparisons, with 
Bonferroni correction. Data which was not normally distributed was log transformed prior to statistical analyses (catalase activity and $\mathrm{LOOH})$. Statistical significance was accepted at the $\mathrm{p}<0.05$ level.

\section{Results}

\section{Changes in exercise volume, macronutrient intake and health \& fitness parameters}

Total training volume for the 9 day period of IT increased from $9.3 \pm 2.4 \mathrm{~h} /$ week (baseline training load) to $23.5 \pm 3.4 \mathrm{~h} /$ week $(\mathrm{p}<0.0001)$, and time spent exercising at high-intensity $\left(>82 \% \mathrm{HR}_{\mathrm{MAX}}\right)$ increased from 2.6 $\pm 2.5 \mathrm{~h} /$ week (baseline training load) to $6.5 \pm 4.0 \mathrm{~h} /$ week $(\mathrm{p}<.0001)$. No statistical differences in these parameters were observed between $\mathrm{M}-\mathrm{CHO}$ and $\mathrm{H}-\mathrm{CHO}$ conditions.

Changes in daily macronutrient intake are reported in Table 3. Daily average CHO and total energy intake were significantly lower in the $\mathrm{M}-\mathrm{CHO}$ condition compared with the $\mathrm{H}-\mathrm{CHO}$ condition (carbohydrate effects: all p 0.039). Average $\mathrm{CHO}$, sugar, protein, and total energy intake increased during days 7-9, relative to days 1-6 (period effects: $\mathrm{p}<0.016$ ). No differences were observed in fat intake between $\mathrm{H}-\mathrm{CHO}$ and $\mathrm{M}-\mathrm{CHO}$ conditions or across the periods assessed. Period*Carbohydrate interaction effects were observed for changes in daily average $\mathrm{CHO}$ consumption $\left(\mathrm{F}_{1,9}=11.2, \mathrm{p}=0.009\right)$ and total energy intake $\left(\mathrm{F}_{1,9}=5.7, \mathrm{p}=0.041\right)$. Pairwise comparisons revealed that average $\mathrm{CHO}(\mathrm{p}=0.02)$ and total energy intake $(\mathrm{p}=0.029)$ during days $7-9$ was significantly greater in $\mathrm{H}-\mathrm{CHO}$, relative to $\mathrm{M}-\mathrm{CHO}$.

No significant changes in the participants' body mass were noted across either period of IT (mean body mass change: $+0.3 \pm 1.0 \mathrm{~kg}(\mathrm{H}-\mathrm{CHO})$ and $-0.5 \pm 0.9 \mathrm{~kg}(\mathrm{M}-\mathrm{CHO}))$.

\section{Resting changes in markers of plasma oxidative stress}

Changes in resting concentrations of $\mathrm{PC}, \mathrm{LOOH}$ and TAC, and enzyme activities of CAT and $-\mathrm{SH}$ following 9 days of IT are shown for both $\mathrm{H}-\mathrm{CHO}$ and $\mathrm{M}-\mathrm{CHO}$ conditions in Figure 2 (panels 1 and 2: A-E). $\operatorname{LogCAT}(\mathrm{p}<0.0001)$ and $-\mathrm{SH}(\mathrm{p}=0.003)$ activities significantly decreased on day 6 , relative to day 2 in the H$\mathrm{CHO}$ and $\mathrm{M}-\mathrm{CHO}$ conditions (day effects, $\operatorname{LogCAT}: \mathrm{F}_{2,24}=16.9, \mathrm{p}<0.0001$ and $-\mathrm{SH}: \mathrm{F}_{2,24}=6.1, \mathrm{p}=0.007$ ). Only LogCAT remained supressed, relative to day 2 on day 10 in the $\mathrm{H}-\mathrm{CHO}$ and $\mathrm{M}-\mathrm{CHO}$ conditions $(\mathrm{p}=0.003)$. PC and $\mathrm{LogLOOH}$ were unaltered in response to IT in both $\mathrm{H}-\mathrm{CHO}$ and $\mathrm{M}-\mathrm{CHO}$ conditions. TAC values were significantly lower in the M-CHO condition on day 10 (Day*CHO interaction effect: $\mathrm{F}_{2,24}=3.6, \mathrm{p}=0.044$ ), relative to day $2(\mathrm{p}=0.048)$ and day $6(\mathrm{p}<0.0001)$. TAC was lower on day $6(-53.8 \mu \mathrm{M}, \mathrm{p}=0.160)$, relative to day 2 in the $\mathrm{H}-\mathrm{CHO}$ condition, although this did not reach statistical significance. 
Changes in exercise-induced plasma oxidative stress

Exercise-induced changes in concentrations of PC, LOOH and TAC, and enzyme activities of CAT and

-SH following 9 days of IT are shown for both H-CHO and M-CHO conditions in Figure 2 (panels 1 and 2: A-

E). Exercise stimulated increases in PC, $\operatorname{LogLOOH}, \mathrm{TAC}$ and LogCAT on all days and in both H-CHO and M-

CHO conditions (time effects, PC: $F_{1,12}=16.9, p=0.014$; LogLOOH: $F_{2,24}=6.1, p=0.007$; TAC: $F_{2,24}=16.9$, $\mathrm{p}<0.0001$ and $\left.\operatorname{LogCAT}: \mathrm{F}_{2,24}=6.1, \mathrm{p}=0.007\right)$. Acute changes in TAC, CAT and $-\mathrm{SH}$ activities were not influenced by IT or CHO condition. Day*Time interaction effects were observed for changes in PC $\left(\mathrm{F}_{2,24}=7.1\right.$, $\mathrm{p}=0.004)$ and $\operatorname{LogLOOH}\left(\mathrm{F}_{2,24}=6.0, \mathrm{p}=0.008\right)$. Pairwise comparisons revealed that the increases in $\operatorname{LogLOOH}$ on day $6(\mathrm{p}=0.001)$ and day $10(\mathrm{p}=0.05)$ were greater than on day 2. Increases in PC were greater on day 6 $(\mathrm{p}=0.001)$ than days 2 and 10 , however post-exercise PC concentrations on day $6(\mathrm{p}=0.006)$ and day 10 $(\mathrm{p}=0.050)$ were greater than on day 2. A Day*Time*CHO interaction effect was observed for $\operatorname{LogLOOH}\left(\mathrm{F}_{2,24}=\right.$ 4.0, $\mathrm{p}=0.032$ ), although pairwise comparisons revealed no statistical differences in the responses in $\mathrm{H}-\mathrm{CHO}$ and M-CHO conditions on different days.

306

\section{Physical performance and psychological mood profiles}

Parameters of physical performance are indicated in Table 2. Average power output $\left(\mathrm{F}_{2,24}=.846\right.$, $\mathrm{p}=0.442$ ) during the 1 hour PT was not different on days 2, 6 and 10. Maximum heart rate during the PT was lower on days $6(\mathrm{p}<0.001)$ and $10(\mathrm{p}=0.011)$, relative to day 2 (Day effect: $\left.\mathrm{F}_{2,24}=10.6, \mathrm{p}<0.001\right)$. All performance and physiological parameters were independent of carbohydrate ingestion during training. (Day effect: $\mathrm{F}_{2,22}=21.1, \mathrm{p}<0.0001$ ) and POMS-65 TMD scores (Day effect: $\mathrm{F}_{2,24}=12.4, \mathrm{p}<0.0001$ ). Both scores increased from day 2 to day 6 (DALDA: +5.1 , POMS-65: +19.4 , both $\mathrm{p}<0.016$ ) and remained elevated above day 2, at day 10 (DALDA: +5.2 , POMS-65: +21.7 , both $\mathrm{p}<0.0001$ ). Both these changes were independent of M$\mathrm{CHO}$ and $\mathrm{H}-\mathrm{CHO}$ conditions.

\section{Discussion}

Studies investigating changes in oxidative stress in response to IT have assessed the effects of training overload over the course of months, taking either observational approaches $(10,39)$ or implementing generic IT regimens $(22,40)$. Based on baseline training loads, the present study implemented personalised IT regimens of 
increased volume (h/week: $+153 \%)$ and intensity $\left(>82 \% \mathrm{HR}_{\mathrm{MAX}}:+146 \%\right)$, to assess the short-term effects of training overload on parameters of resting and exercise-induced oxidative stress in trained male cyclists. The influence of high and moderate carbohydrate ingestion before, during and after IT sessions was also assessed. It was shown that a short-term period of IT caused significant reductions in resting antioxidant capacity after 6 days. In addition, the magnitude of post-exercise increases in protein and lipid markers of oxidative stress was greater on days 6 and 10, relative to baseline. These changes were independent of the carbohydrate composition of beverages ingested before, during or after the IT sessions.

Previous studies have reported that periods of IT, or participants described as OT have higher resting levels of PC $(22,39)$, lipid peroxidation products $(10,22)$ and antioxidant enzyme activity $(22,31)$. In addition, many studies have found that plasma TAC is lower than in non-OT participants $(22,31)$. The current study presents evidence that 9 days of intensified cycling training lowered resting plasma catalase and thiol activities by day 6 and TAC by day 10 ( $\mathrm{p}<0.05$; M-CHO only); however, no alterations were observed in resting PC or LOOH concentrations (Figure 2). The differential pattern of antioxidant response may be explained, in part, by the wide variety of study designs that have been used, including both endurance (31) and/or resistance based programmes (22). Furthermore, the current study assessed resting markers of oxidative stress much closer to the change in overload stimulus (days, as opposed to weeks or months). Between days 2 and 6 of IT, overload appears to have caused a marked initial rise in ROS that subsequently exhausted catalase enzyme function and depleted plasma thiols.

The maintenance of PC and $\mathrm{LOOH}$ concentrations during and following IT may be explained by the training status of the participants. Palazetti et al., showed no changes in resting thiobarbituric acid reactive substances (TBARS), a marker of lipid peroxidation, in response to 4 weeks of endurance-based IT in highly trained triathletes $\left(\dot{v} \mathrm{O}_{2 \max }: 66 \pm 4 \mathrm{ml} / \mathrm{kg} / \mathrm{min}\right)(31)$. Higher aerobic fitness and endogenous antioxidant capacity in trained athletes $(11,16)$ may enable a buffering of protein and lipid biomarker formation during IT, with formation greater in less well trained participants $(10,22,39)$. The vast array of antioxidant enzymes controlling redox balance makes the precise antioxidant mechanisms modulating $\mathrm{PC}$ and LOOH in the current study hard to elucidate. We can speculate that elevated enzyme efficiency as a result of higher training status $(11,16)$ or activation of antioxidant enzymes not measured (i.e. superoxide dismutase and glutathione peroxidase) might explain the apparent paradoxical depletion in catalase and thiol activity and maintenance of PC and LOOH at baseline levels. It must also be reemphasised that the period of IT assessed was much shorter than previous 
studies $(22,31)$, suggesting that heightened $\mathrm{PC}$ and $\mathrm{LOOH}$ formation may occur further along the overtraining continuum $(10,22,39)$.

The current study assessed exercise-induced changes in oxidative stress in response to three fasted PTs, both during (days 2 and 6) and immediately after the period of IT (day 10). All PTs elicited significant increases in oxidative stress (CAT, TAC, PC and $\mathrm{LOOH}$ ), with the magnitude of increase in PC and $\mathrm{LOOH}$ greater on days 6 and 10, relative to day 2. Some previous investigations have shown that a period of IT can exaggerate acute increases in oxidative stress $(31,40)$. Indeed, lower resting thiol and catalase activities in the current study may have provided less protection against the formation of PC and LOOH following PTs on days 6 and 10 respectively. Interestingly, the magnitude of increase in PC was greater on day 6, than on day 10, suggesting a degree of habituation to training overload by the end of the IT period. It must be noted that other studies in OT humans $(39)$ and animals $(28,29)$ have shown supressed oxidative stress following a single bout of exercise, indicative of a maladaptive response. Overtraining is a complex phenomenon, which is hard to classify with a single variable. Indeed, data from the current study reports that IT elicited decrements in psychological mood state, but did not significantly affect exercise performance (Table 2), making it hard to specify whether participants were OT per se. Therefore, the discrepancies in findings between various investigations may be explained by fundamental differences in study design and classifications of training overload and overtraining.

An additional aim of the current study was to assess the impact of high ( $\mathrm{H}-\mathrm{CHO})$ or moderate $(\mathrm{M}-\mathrm{CHO})$ CHO ingestion before, during and after IT sessions on resting and exercise-induced oxidative stress. Carbohydrate composition of the IT beverages had no impact on subsequent oxidative stress responses to any of the fasted PT's, supporting some previous work reporting no effect of $\mathrm{CHO}$ intake on exercise-induced oxidative stress $(27,42)$. With regards to changes in resting oxidative stress, we did observe that high $\mathrm{CHO}$ consumption before, during and after IT sessions ( $\mathrm{H}-\mathrm{CHO})$ prevented the decline in resting TAC by day 10 . The decrease in TAC between days 6 and 10 in M-CHO suggests that non-enzymatic antioxidants were strongly consumed during this IT period, supporting results from previous IT studies $(22,31)$. Higher CHO (44 g vs. $10 \mathrm{~g})$ and also protein intake $(17 \mathrm{~g} v s .0 \mathrm{~g})$ in the immediate recovery period following each IT session explains, in part, the maintenance of plasma antioxidant status in $\mathrm{H}-\mathrm{CHO}$ and not M-CHO. Furthermore, daily energy intake and $\mathrm{CHO}$ consumption (g/day) between days 7 and 9 was also significantly greater in the $\mathrm{H}-\mathrm{CHO}$ condition (Table 3). Additional adenosine triphosphate (ATP) supply during IT-induced metabolic stress, may have maintained plasma uric acid concentrations, a degradation product of ATP which largely contributes (approximately 60\%) to plasma TAC status (5). 

amount of carbohydrate throughout the 9-day period of IT, despite lower daily intakes compared to the high carbohydrate group (M-CHO: $8.21 \mathrm{~g} / \mathrm{kg}$ of body weight vs. H-CHO: $9.67 \mathrm{~g} / \mathrm{kg}$ body weight). Given that the period of administered training overload was not deemed overtraining per se, this dosage of carbohydrate may have been sufficient to modulate changes in oxidative stress as result of IT. In addition, we must acknowledge that the additional protein added to the recovery beverage in the H-CHO condition only (Table 1) complicated aspects of the study design. No condition-dependent effects were observed with regards to changes in resting markers of oxidative stress between days 2 and 6 . However, the additional protein in the $\mathrm{H}-\mathrm{CHO}$ condition may have aided the regeneration of intracellular antioxidants, such as glutathione following exercise (23). This makes it hard to elucidate the precise mechanism behind the maintenance of plasma TAC in this condition.

391

\section{Conclusions}

The present data demonstrates that a 9-day period of IT, in which training volume and intensity were markedly increased, caused reductions in resting plasma catalase and thiol activities and exacerbated acute increases in protein carbonylation and lipid peroxidation following exhaustive exercise. Importantly, resting and exercise-induced changes in these markers was not influenced by the different carbohydrate beverages ingested before, during and after training sessions.

\section{Acknowledgments} design of the investigation. This study formed part of a larger investigation that assessed parameters of hormonal balance and immune function $(19,38)$ and in addition, the quality of sleep during short-term intensified training was monitored (18). Changes in resting and exercise-induced oxidative stress were retrospective analyses proposed by Dr Alex Wadley. All data collection was carried out by Dr Sophie Killer and Ida Svendsen. All laboratory and statistical analysis were performed by Dr Alex Wadley. Drafting of the article was by Dr Alex Wadley and editing of the final version was carried out by all authors. This work was partially 


\section{Conflict of Interest}

411 None of the authors declare a conflict of interest.

\section{References}

1. Achten J, Halson SL, Moseley L, Rayson MP, Casey a, Jeukendrup a E. Higher dietary carbohydrate content during intensified running training results in better maintenance of performance and mood state. [Internet]. J. Appl. Physiol. 2004;96(4):1331-40.[cited 2014 Sep 10 ] Available from: http://www.ncbi.nlm.nih.gov/pubmed/14660506

2. Benzie IF, Strain JJ. The ferric reducing ability of plasma (FRAP) as a measure of "antioxidant power": the FRAP assay [Internet]. Anal. Biochem. 1996;239(1):70-6.Available from: http://www.ncbi.nlm.nih.gov/pubmed/8660627

3. Bloomer RJ, Davis PG, Consitt LA, Wideman L. Plasma protein carbonyl response to increasing exercise duration in aerobically trained men and women [Internet]. Int. J. Sports Med. 2007;28(1):215.Available from: <Go to ISI>://000243359800004

4. Buss H, Chan TP, Sluis KB, Domigan NM, Winterbourn CC. Protein carbonyl measurement by a sensitive ELISA method [Internet]. Free Radic. Biol. Med. 1997;23(3):361-6.Available from: <Go to ISI >://A1997XG67400002

5. Cao G, Prior RL. Comparison of different analytical methods for assessing total antioxidant capacity of human serum. [Internet]. Clin. Chem. 1998;44(6 Pt 1):1309-15.Available from: http://www.ncbi.nlm.nih.gov/pubmed/9625058

6. Carty JL, Bevan R, Waller H, et al. The effects of vitamin C supplementation on protein oxidation in healthy volunteers [Internet]. Biochem Biophys Res Commun 2000;273(2):729-35.Available from: http://www.ncbi.nlm.nih.gov/pubmed/10873672

7. El-Saadani M, Esterbauer H, El-Sayed M, Goher M, Nassar AY, Jurgens G. A spectrophotometric assay for lipid peroxides in serum lipoproteins using a commercially available reagent [Internet]. J. Lipid Res. 1989;30(4):627-30.Available from: http://www.ncbi.nlm.nih.gov/pubmed/2754343

8. Faul F, Erdfelder E, Lang AG, Buchner A. G*Power 3: a flexible statistical power analysis program for the social, behavioral, and biomedical sciences. [Internet]. Behav. Res. Methods 2007;39(2):17591.Available from: http://www.ncbi.nlm.nih.gov/pubmed/17695343

9. Ferreira LF, Reid MB. Muscle-derived ROS and thiol regulation in muscle fatigue. [Internet]. J. Appl. Physiol. 2008;104(3):853-60.[cited 2014 Oct 31 ] Available from: http://www.ncbi.nlm.nih.gov/pubmed/18006866 
11. Gomez-Cabrera MC, Domenech E, Vina J. Moderate exercise is an antioxidant: upregulation of antioxidant genes by training [Internet]. Free Radic Biol Med 2008;44(2):126-31.Available from: http://www.ncbi.nlm.nih.gov/pubmed/18191748

12. Grove JR. Preliminary evidence for the reliability and validity of an abbreviated Profile of Mood States. Int. J. Sport Psychol. 1992;23(2):93-109.

13. Halson SL, Lancaster GI, Achten J, Gleeson M, Jeukendrup AE. Effects of carbohydrate supplementation on performance and carbohydrate oxidation after intensified cycling training. [Internet]. J. Appl. Physiol. 2004;97(4):1245-53.[cited 2014 Sep 10 ] Available from: http://www.ncbi.nlm.nih.gov/pubmed/15155717

14. Howley ET, Bassett Jr DR, Welch HG. Criteria for maximal oxygen uptake: a review and commentary. Med. Sci. Sport. Exerc. 1995;27(9):1292-301.

15. Jeukendrup A. A step towards personalized sports nutrition: carbohydrate intake during exercise. [Internet]. Sports Med. 2014;44 Suppl 1:S25-33.[cited 2014 Jul 14 ] Available from: http://www.ncbi.nlm.nih.gov/pubmed/24791914

16. Ji LL. Modulation of skeletal muscle antioxidant defense by exercise: Role of redox signaling. [Internet]. Free Radic. Biol. Med. 2008;44(2):142-52.[cited 2012 Mar 26 ] Available from: http://www.ncbi.nlm.nih.gov/pubmed/18191750

17. Khassaf M, Child RB, McArdle A, Brodie D a, Esanu C, Jackson MJ. Time course of responses of human skeletal muscle to oxidative stress induced by nondamaging exercise. [Internet]. J. Appl. Physiol. 2001;90(3):1031-5.Available from: http://www.ncbi.nlm.nih.gov/pubmed/11181616

18. Killer, S.C., Svendsen, I.S., Jeukendrup, A.E. Gleeson M. Evidence of disturbed sleep and mood state in well-trained athletes during short-term intensified training with and without a high carbohydrate nutritional intervention. Prep. 2014;

19. Killer, S.C., Svendsen, I.S., Randell, R.K., Carter, J.M., Jeukendrup, A.E., Gleeson M. The impact of 9 days of intensified training with a high carbohydrate feeding strategy on hormonal balance and immune function in trained. Med. Sci. Sport. Exerc. (In Rev. 2014;

20. Lamb GD, Westerblad H. Acute effects of reactive oxygen and nitrogen species on the contractile function of skeletal muscle. J. Physiol. 2011;589(September 2010):2119-27.

21. Lamprecht M, Greilberger JF, Schwaberger G, Hofmann P, Oettl K. Single bouts of exercise affect albumin redox state and carbonyl groups on plasma protein of trained men in a workload-dependent manner [Internet]. J Appl Physiol 2008;104(6):1611-7.[cited 2012 Jan 4 ] Available from: http://www.ncbi.nlm.nih.gov/pubmed/18420715

22. Margonis K, Fatouros IG, Jamurtas AZ, et al. Oxidative stress biomarkers responses to physical overtraining: implications for diagnosis. [Internet]. Free Radic. Biol. Med. 2007;43(6):901-10.[cited 2014 Sep 7 ] Available from: http://www.ncbi.nlm.nih.gov/pubmed/17697935

23. Mariotti F, Simbelie KL, Makarios-lahham L, Laplaize B, Tome D, Even PC. Acute Ingestion of Dietary Proteins Improves Post-Exercise Liver Glutathione in Rats in a Dose- Dependent Relationship with their Cysteine Content. J. Nutr. 2004;134:128-31.

24. McAnulty S, McAnulty L, Nieman D, Morrow J, Dumke C, Utter a. Carbohydrate effect: Hormone and oxidative changes. Int. J. Sports Med. 2007;28:921-7. 
25. McAnulty SR, McAnulty LS, Morrow JD, Nieman DC, Owens JT, Carper CM. Influence of carbohydrate, intense exercise, and rest intervals on hormonal and oxidative changes. Int. J. Sport Nutr. Exerc. Metab. 2007;17:478-90.

26. McAnulty SR, McAnulty LS, Morrow JD, et al. Effect of daily fruit ingestion on angiotensin converting enzyme activity, blood pressure, and oxidative stress in chronic smokers [Internet]. Free Radic Res 2005;39(11):1241-8.Available from: http://www.ncbi.nlm.nih.gov/pubmed/16298751

27. McAnulty SR, McAnulty LS, Nieman DC, et al. Influence of Carbohydrate Ingestion on Oxidative Stress and Plasma Antioxidant Potential Following a 3 h Run [Internet]. Free Radic. Res. 2003;37(8):835-40.Available from: http://informahealthcare.com/doi/abs/10.1080/1071576031000136559

28. Ogonovszky H, Berkes I, Kumagai S, et al. The effects of moderate-, strenuous- and over-training on oxidative stress markers, DNA repair, and memory, in rat brain [Internet]. Neurochem. Int. 2005;46(8):635-40. [cited 2014 Feb 7 ] Available from: http://linkinghub.elsevier.com/retrieve/pii/S0197018605000665

29. Ogonovszky H, Sasvári M, Dosek A, et al. The effects of moderate, strenuous, and overtraining on oxidative stress markers and DNA repair in rat liver. [Internet]. Can. J. Appl. Physiol. 2005;30(2):18695.Available from: http://www.ncbi.nlm.nih.gov/pubmed/15981787

30. Packer L. Oxidants, antioxidant nutrients and the athlete [Internet]. J Sport. Sci 1997;15(3):35363.Available from: http://www.ncbi.nlm.nih.gov/pubmed/9232561

31. Palazzetti S, Richard M-J, Favier A, Margaritis I. Overloaded training increases exercise-induced oxidative stress and damage. [Internet]. Can. J. Appl. Physiol. 2003;28(4):588-604.Available from: http://www.ncbi.nlm.nih.gov/pubmed/12904636

32. Powers SK, Jackson MJ. Exercise-induced oxidative stress: cellular mechanisms and impact on muscle force production [Internet]. Physiol Rev 2008;88(4):1243-76.[cited 2011 Jul 27 ] Available from: http://www.pubmedcentral.nih.gov/articlerender.fcgi?artid=2909187\&tool=pmcentrez\&rendertype=abst ract

33. Radak Z, Chung HY, Goto S. Exercise and hormesis: oxidative stress-related adaptation for successful aging. [Internet]. Biogerontology 2005;6(1):71-5.[cited 2013 Aug 8 ] Available from: http://www.ncbi.nlm.nih.gov/pubmed/15834665

34. Radak Z, Kaneko T, Tahara S, et al. The effect of exercise training on oxidative damage of lipids, proteins, and DNA in rat skeletal muscle: evidence for beneficial outcomes [Internet]. Free Radic Biol Med 1999;27(1-2):69-74.Available from: http://www.ncbi.nlm.nih.gov/pubmed/10443921

35. Rodriguez NR, DiMarco. NM, Langley. S. Nutrition and Athletic Performance. Med. Sci. Sport. Exerc. 2009;Joint Posi:709-31.

36. Rushall BS. A tool for measuring stress tolerance in elite athletes. J. Appl. Sport Psychol. 1990;2(1)

37. Smith PK, Krohn RI, Hermanson GT, et al. Measurement of protein using bicinchoninic acid [Internet]. Anal. Biochem. 1985;150(1):76-85.Available from: http://www.ncbi.nlm.nih.gov/pubmed/3843705

38. Svendsen, IS, Killer, SC, Carter, J, Randell, RK, Jeukendrup, AE., Gleeson M. Effect of intensified training with two different carbohydrate nutritional interventions on immune function and markers of overreaching in highly trained cyclists. Prep. 2014; 
39. Tanskanen M, Atalay M, Uusitalo A. Altered oxidative stress in overtrained athletes. [Internet]. $J$. Sports Sci. 2010;28(3):309-17.[cited 2014 Sep 8 ] Available from: http://www.ncbi.nlm.nih.gov/pubmed/20077275

40. Tanskanen MM, Uusitalo AL, Kinnunen H, Häkkinen K, Kyröläinen H, Atalay M. Association of military training with oxidative stress and overreaching. [Internet]. Med. Sci. Sports Exerc. 2011;43(8):1552-60.[cited 2014 Sep 8 ] Available from: http://www.ncbi.nlm.nih.gov/pubmed/21266928

41. Turner JE, Bosch JA, Drayson MT, Aldred S. Assessment of oxidative stress in lymphocytes with exercise. [Internet]. J. Appl. Physiol. 2011;111(1):206-11.[cited 2013 Feb 4 ] Available from: http://www.ncbi.nlm.nih.gov/pubmed/21493722

42. Vasankari T, Kujala U, Sarna S, Ahotupa M. Effects of ascorbic acid and carbohydrate ingestion on exercise induced oxidative stress [Internet]. J. Sports Med. Phys. Fitness 1998;38(4):281-5.Available from: http://europepmc.org/abstract/MED/9973769

43. Wadley AJ, Chen YW, Bennett SJ, et al. Monitoring changes in thioredoxin and over-oxidised peroxiredoxin in response to exercise in humans. Free Radic Res 2015; In Press

44. Wadley AJ, Veldhuijzen van Zanten JJCS, Paine NJ, Drayson MT, Aldred S. Underlying inflammation has no impact on the oxidative stress response to acute mental stress. [Internet]. Brain. Behav. Immun. 2014; [cited 2014 Apr 30 ] Available from: http://www.ncbi.nlm.nih.gov/pubmed/24675034

45. Wadley AJ, van Zanten JJCSV, Stavropoulos-Kalinoglou A, et al. Three months of moderate-intensity exercise reduced plasma 3-nitrotyrosine in rheumatoid arthritis patients. [Internet]. Eur. J. Appl. Physiol. 2014; [cited 2014 Apr 30 ] Available from: http://www.ncbi.nlm.nih.gov/pubmed/24719046

46. Zoppi CC, Macedo D V. Overreaching-induced oxidative stress, enhanced HSP72 expression, antioxidant and oxidative enzymes downregulation. [Internet]. Scand. J. Med. Sci. Sports 2008;18(1):67-76.[cited 2014 Sep 8 ] Available from: http://www.ncbi.nlm.nih.gov/pubmed/17346286 
561 Table 1: Composition of the high and moderate carbohydrate training solutions

\begin{tabular}{ccccccc}
\hline & \multicolumn{3}{c}{ High Carbohydrate } & \multicolumn{3}{c}{ Moderate Carbohydrate } \\
& Pre & During & Post & Pre & During & Post \\
& 98 & 250 & 250 & 12 & 100 & 50 \\
$\begin{array}{c}\text { Energy } \\
\text { (Kcal) }\end{array}$ & 24 & 60 & 44 & 2 & 20 & 10 \\
$\begin{array}{c}\text { Carbohydrate (g) } \\
\begin{array}{c}\text { Protein } \\
(\text { g) }\end{array}\end{array}$ & 0 & 0 & 17 & 0 & 0 & 0 \\
\hline
\end{tabular}

562

Table 1 Footnote: Values are in Kcal (energy of solution) and grams (carbohydrate and protein content) for the pre, during and post-exercise solutions.

Table 2: Changes in performance trial parameters

High Carbohydrate

\section{Moderate Carbohydrate}

\begin{tabular}{|c|c|c|}
\hline & Day 6 & Day $10 \quad$ Day 2 \\
\hline
\end{tabular}

\begin{tabular}{|c|c|c|c|c|c|c|}
\hline $\begin{array}{c}\text { Average } \\
\text { Workload } \\
\text { (Watts) }\end{array}$ & $254 \pm 35$ & $249 \pm 33$ & $253 \pm 32$ & $247 \pm 34$ & $238 \pm 36$ & $240 \pm 34$ \\
\hline $\begin{array}{l}\text { Maximum } \\
\text { Heart Rate } \\
\quad(\text { bpm })\end{array}$ & $158 \pm 13$ & $148 \pm 15 * * *$ & $150 \pm 13^{*}$ & $159 \pm 13$ & $148 \pm 15 * * *$ & $158 \pm 14^{*}$ \\
\hline
\end{tabular}

568

569 Table 2 Footnote: Values are means \pm standard deviation * indicates significant difference, relative to day 2: * $570 \mathrm{p}<.05 ; * * * \mathrm{p}<.0001)$. 


\begin{tabular}{|c|c|c|c|c|}
\hline & \multicolumn{2}{|c|}{ High Carbohydrate } & \multicolumn{2}{|c|}{ Moderate Carbohydrate } \\
\hline & Days 1-6 & Days 7-9 & Days 1-6 & Days 7-9 \\
\hline $\begin{array}{c}\text { Total Energy Intake } \\
\text { (Kcal/day) }\end{array}$ & $3787 \pm 277$ & $4597 \pm 372 *^{+}$ & $3524 \pm 237$ & $3864 \pm 289^{*}$ \\
\hline Carbohydrate (g/day) & $611 \pm 42$ & $738 \pm 50^{*^{+}}$ & $552 \pm 36$ & $593 \pm 38^{*}$ \\
\hline Fat (g/day) & $91 \pm 10$ & $110 \pm 12$ & $91 \pm 12$ & $104 \pm 13$ \\
\hline Sugar (g/day) & $310 \pm 37$ & $379 \pm 38^{*^{+}}$ & $237 \pm 28$ & $261 \pm 34^{*}$ \\
\hline Protein (g/day) & $127 \pm 12$ & $155 \pm 21^{*^{+}}$ & $115 \pm 10$ & $134 \pm 12 *$ \\
\hline
\end{tabular}
the $\mathrm{H}-\mathrm{CHO}$ and $\mathrm{M}-\mathrm{CHO}$ conditions: $\left.{ }^{+} \mathrm{p}<.05\right)$.

579 
Fig 1: Schematic representation of the study design. A: In this randomized crossover and double-blinded study design, participants engaged in two 9-day periods of intensified exercise training whilst ingesting high (H$\mathrm{CHO}$ ) or moderate (M-CHO) carbohydrate solutions before, during and after each training session. Conditions

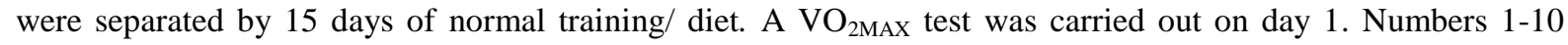
represent days. B: Blood samples ( $\uparrow$ ) were taken before (pre) and immediately after (post) a 1 hour performance trial (days 2, 6 and 10) in a fasted state.

598

599

Fig 2: Changes in resting and exercise-induced changes in plasma markers of oxidative stress. Bars represent nmol/mg protein (PC, 1A), nM (LOOH, 1B), uM (TAC, 1C), nmol/min/ml (LogCAT, 1D) and uM oxidised NADPH (-SH, 1E) in plasma before (pre-exercise) and after exercise (post-exercise) on day 2 (black bars), day 6 (white bars) and day 10 (grey bars). Values are means \pm standard error. ${ }^{+}$indicates a significant difference in resting levels, relative to day $2:{ }^{+} \mathrm{p}<.05 ;{ }^{++} \mathrm{p}<.01 ;{ }^{+++} \mathrm{p}<.0001 .{ }^{\#}$ indicates a significant difference in resting levels, relative to day $6:{ }^{\# \#} \mathrm{p}<.0001 . *$ indicates significant differences post-exercise, relative to baseline: $2:{ }^{\$} \mathrm{p}<.05 ;{ }^{\$} \mathrm{p}<.01$.

607

608

609

610

611 
A

Intensified 9-day training period (High Carbohydrate)

\begin{tabular}{l|l|}
$\mathrm{VO}_{2}$ & Time \\
$\mathbf{m a x}$ & Trial
\end{tabular}

1

Time
Trial

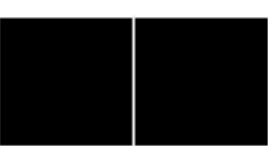

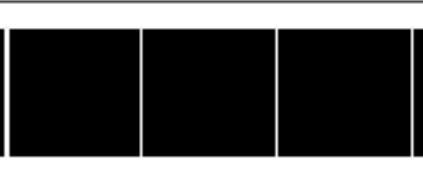

3

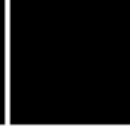

Performance Trial

Time

Trial

10

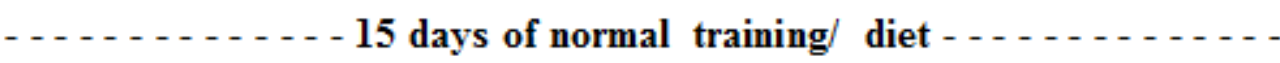

Intensified 9-day training period (Moderate Carbohydrate)

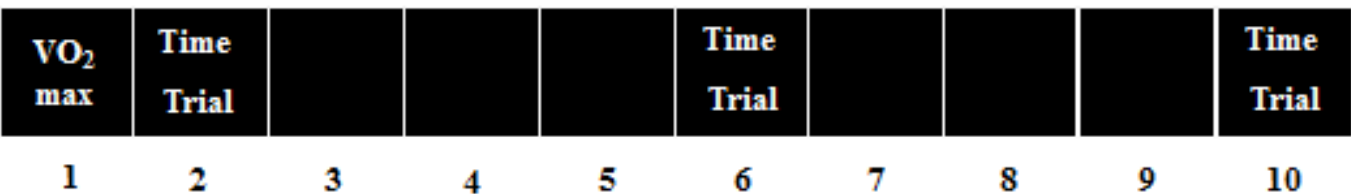


1. High Carbohydrate

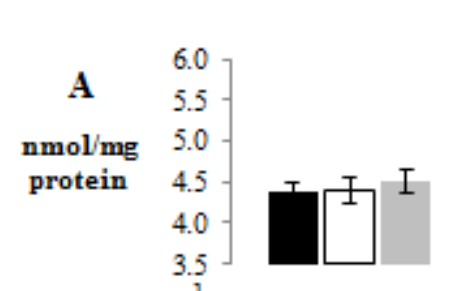

B

Log

LOOH

(nM)

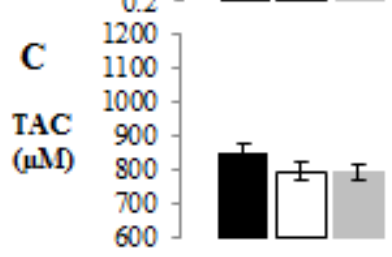

D 2.1

Dog CAT $\begin{array}{cc}\text { (nmol } & 1.3 \\ \mathbf{m i n} / \mathbf{m l}) & 0.9\end{array}$

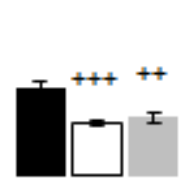

E 180

Thiol

(uM

NADPH
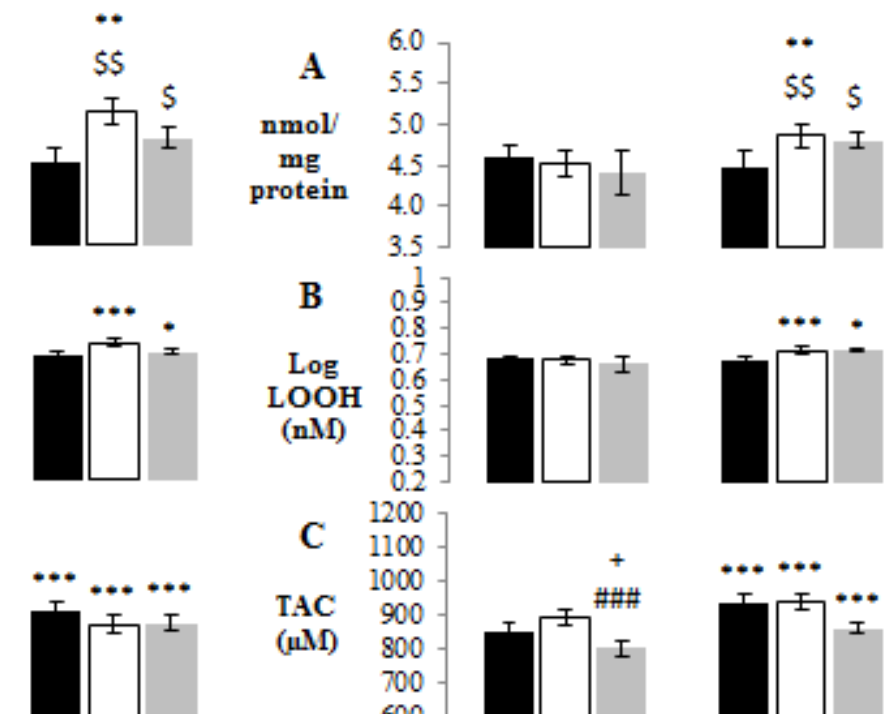

C

1200

1100

TAC 1000

TAC $900-1 . .$.

(IIM) 800
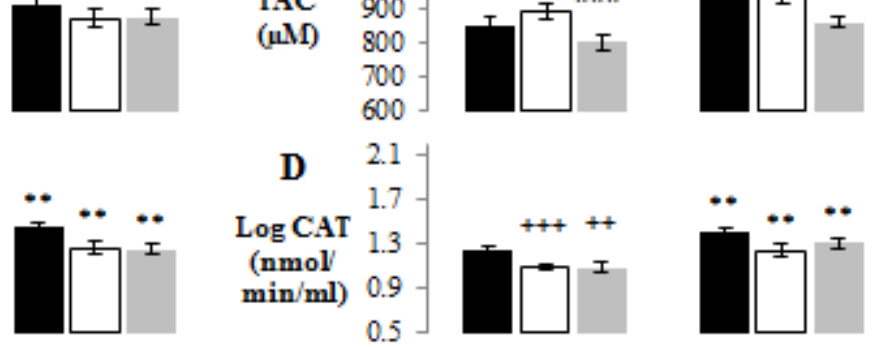

D 2.1

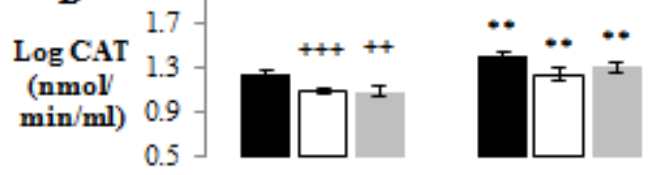

E $\quad 180$

Thiol
(uM 130 oxidised NADPH)

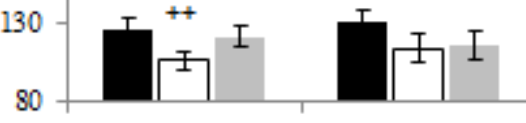

